\title{
Analysis of a Hybrid Renewable Energy Stand-Alone Unit for Simultaneously Producing Hydrogen and Fresh Water from Sea Water
}

\author{
Ashraf Balabel ${ }^{a, b}$, Hamdy Kotb ${ }^{b}$ \\ ${ }^{a}$ Mechanical Engineering Dept, Faculty of Engineering, Taif University, Taif, Kingdom of Saudi Arabia. \\ ${ }^{b}$ Mechanical Power Engineering Dept., Faculty of Engineering, Menoufiya University, Shebin El-Kom, Egypt
}

\begin{abstract}
The present paper proposes a new imaging of a stand-alone unit for the simultaneously production of fresh water and hydrogen gas from sea water and brackish water. The proposed stand-alone unit can contribute effectively to the integrated water policy in Egypt's present and future. The fresh water is produced using desalination with reverse osmosis technologies driven by renewable energy systems. This is thought to be the optimum solution to the potable water scarcity at remote areas characterized by the lack of conventional energy sources like heat and electricity grid. Different new electrochemical concepts for hydrogen production from the produced brine stream are illustrated with the emphasis on the safely removal of the evolved chlorine. Electricity used, either for driving high-pressure pumps or for ionization of salts contained in the sea water, is produced from a hydrogen fuel cell unit. The proposed stand-alone unit can become widely utilized not just for drinking water applications but for industrial process applications where high purity is demand.
\end{abstract}

Keywords: Desalination, hydrogen production, hydrogen fuel cell, reverse osmosis system, sea wate.

\section{Introduction}

Water is one of the most abundant resources on earth, covering three-quarters of the planet's surface. However, about $97 \%$ of the earth's water is salt water in the oceans, and a tiny $3 \%$ is fresh water. This small percentage of the earth's water, which supplies most of human, animal and plants needs, exists in ground water, lakes and rivers. Nearly, $70 \%$ from this tiny $3 \%$ of the world's fresh water is frozen in glaciers, permanent snow cover, ice and permafrost. Thirty percent of all fresh water is underground, most of it in deep, hard-to-reach aquifers. Lakes and rivers together contain just a little more than $0.25 \%$ of all fresh water; lakes contain most of it [1].

According to the population growth in Egypt and the increased industrial development, there is a large escalation of demand for fresh water. Nearly $99 \%$ of Egypt's population is located in nearly $6 \%$ of Egypt's area in the Nile Valley and Delta. The rest of Egypt's areas are identified as having a crucial situation regarding fresh water supply. These areas are in Sinai, Red Sea coast and Northern Desert coast. The economical development in these areas is basically based on water availability.

Corresponding author. Assoc. Prof. Ashraf Balabel,

Tel. 00201006768952, Fax. 0020482235695;

E-mail: ashrafbalabel@yahoo.com.

(C) 2013 International Association for Sharing Knowledge and Sustainability

DOI: $10.5383 /$ ijtee.06.02.002
The rapid industrial growth and the population explosion all over the world have resulted in the problem of pollution of rivers and lakes by industrial wastes and the large amounts of sewage discharged. On a global scale, man-made pollution of natural sources of water is becoming the single largest cause for fresh water shortage. The only nearly inexhaustible sources of water are the oceans and seas. Their main drawback, however, is their high salinity. Therefore, it would be attractive to tackle the water-shortage problem with desalination of this water. Desalination is the process of removing salt and other minerals or chemicals from seawater and it is one of the alternative sources for fresh water available today. According to World Health Organization (WHO), the permissible limit of salinity in water is $500 \mathrm{mg} / \mathrm{l}$ and for special cases up to 1000 $\mathrm{mg} / \mathrm{l}$, while most of the water available on earth has salinity up to $10,000 \mathrm{mg} / \mathrm{l}$, and sea water normally has salinity in the range of $35,000-45,000 \mathrm{mg} / \mathrm{l}$ in the form of total dissolved salts [2]. Desalination provides water for domestic purposes, industrial processing, agricultural irrigation, etc. 
Desalination in Egypt has been recently initiated for fresh water supply in the petroleum and energy sectors. Most of such installations are dependent on evaporation plants. More recently, a large number of reverse osmosis (RO) plants have become started in different economic sectors.

Egypt has long shorelines of about $2,450 \mathrm{~km}$ on both the Mediterranean and the Red Sea. Salt concentration in the Mediterranean waters is about $35,000 \mathrm{mg} / \mathrm{l}$, while in the Red Sea it is about $40,000 \mathrm{mg} / \mathrm{l}$. Desalination of seawater is being practiced in Egypt in some locations along the Mediterranean coast, the Red Sea coast, and in north and south Sinai.

The most conventional desalination technologies are membrane processes (Reverse Osmosis RO) and Thermal Desalination (Multi Stage Flash-MSF-and Multi Effect Evaporation-MEEsystems). The membrane treatment process used to separate dissolved solutes from water and describes any pressure-driven membrane that uses preferential diffusion for separation. Reverse osmosis and electrodialysis are the two most important membrane processes. The seawater reverse osmosis (RO) desalination is an attractive and viable method for the production of fresh water in many areas, [3].

The integrated water policy in Egypt is dependent on expanding its seawater desalination and setting up efforts to discover additional sources of groundwater. Moreover, the current research of desalination is directed to develop new technologies in order to reduce the cost of water desalination to less than LE 4 per cubic meter. This can be achieved by improving the desalination system components and the developing of renewable energy technologies.

The RO system depends on the properties of semi-permeable membranes which, when used to separate water from a salt solution, allow fresh water to pass into the brine compartment under the influence of osmotic pressure. If a pressure in excess of this value is applied to the salty solution, fresh water will pass from the brine into the water compartment.

Theoretically, the energy is required to pump the feed water at a pressure above the osmotic pressure. In practice, higher pressures must be used, typically $50-80$ atm, in order to have a sufficient amount of water pass through a unit area of membrane [4].

Recently, a RO desalination system has been extensively investigated both theoretically and experimentally in the hydraulic machines Labs, Faculty of Engineering, Menoufiya University [5]. A theoretical model has been developed on the basis of a general mass material and energy balance which have been applied to each part of the RO desalination system. This theoretical model described the unit performance in terms of its membrane dimensions (length and diameter), operating conditions (feed pressure and feed temperature) and feed specifications (feed concentration and feed flow rate). An experimental test set-up has been also designed, fabricated and assembled; in order to carry out the required experimental runs. Simultaneously, a general method has been developed to optimize the module surface area, system structure and operating condition. For more details, one can see the published work [6-7]. The future research can be directed either to the development of an experimental unit to cover a wide range of sea water concentration or to the construction and operation of renewable energy powered RO desalination systems.
Recently, the renewable energy becomes a reality thanks as well as a very common topic to energy research in Egypt as it is now being the key solution of different energy problems including global warming, poor air quality and dwindling reserves of liquid hydrocarbon fuels.

Hydrogen energy is considered one of the recent energy solutions that offer great advantages over many traditional energy resources. Hydrogen can be considered as the energy carrier of the future as well as a storage medium $[8,9,10]$.

The term hybrid energy system can be referred to those applications in which multiple energy sub-systems conversion devices are connected together in such a way to produce the required energy. Such systems are often found in isolated applications and usually include at least on renewable energy source.

In the present work, a new model for a stand-alone unit of hybrid renewable energy powered reverse osmosis desalination system, given here the abbreviation (HRE-RO), is developed. The characteristics of the different suitable system components are given as follows in details. Finally, a model for the selected system components is proposed.

\section{Cycles of HRE-RO Desalination System}

The proposed HRE-RO system consists of two different major systems; one for producing electricity from renewable energy sources and the other for RO system. The RO system is consisted of four stages, namely; pretreatment, high-pressure pumping, membrane assembly, post-treatment process. Figure 1 shows a typical flow diagram of a RO system.

Fig. 1 illustrates the OR system, where the feed is pressurized by a high-pressure pump and made to flow across the membrane surface. Part of this feed passes through the membrane, where the majority of the dissolved solids are removed. The remainder, together with the remaining salts, is rejected at high pressure. In larger plants, it is economically viable to recover the rejected brine energy with a suitable brine turbine. Such systems are called energy recovery reverse osmosis (ER-RO) systems.

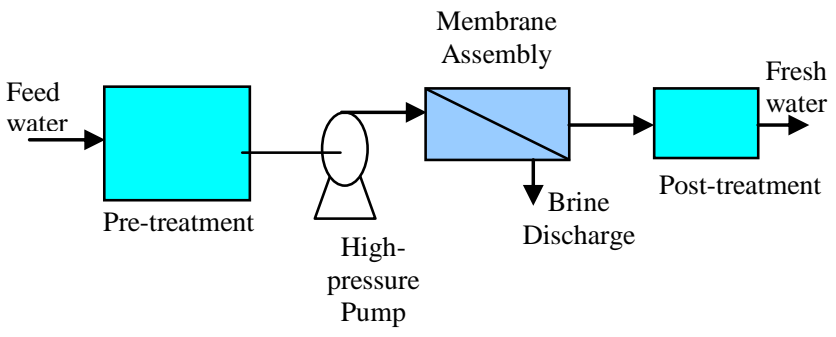

Fig. 1. Flow Diagram of a Reverse Osmosis System.

The proposed hybrid renewable energy system, required for operating the RO system, is a combination of two subsystems. The first subsystem is the Solar-Hydrogen production unit and the second subsystem is a hydrogen fuel cell unit to produce electricity, as shown in Fig.2. The combination between the two systems by adding some suitable components illustrate the proposed HRE-RO system. The description of such system will be described in the following section. 


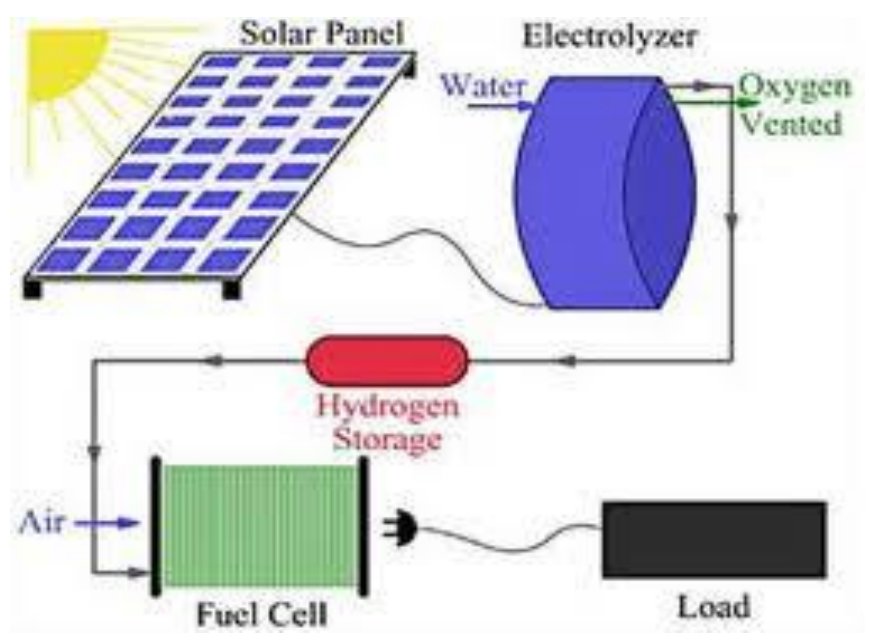

Fig. 2. Solar-Hydrogen-Electricity generation systems

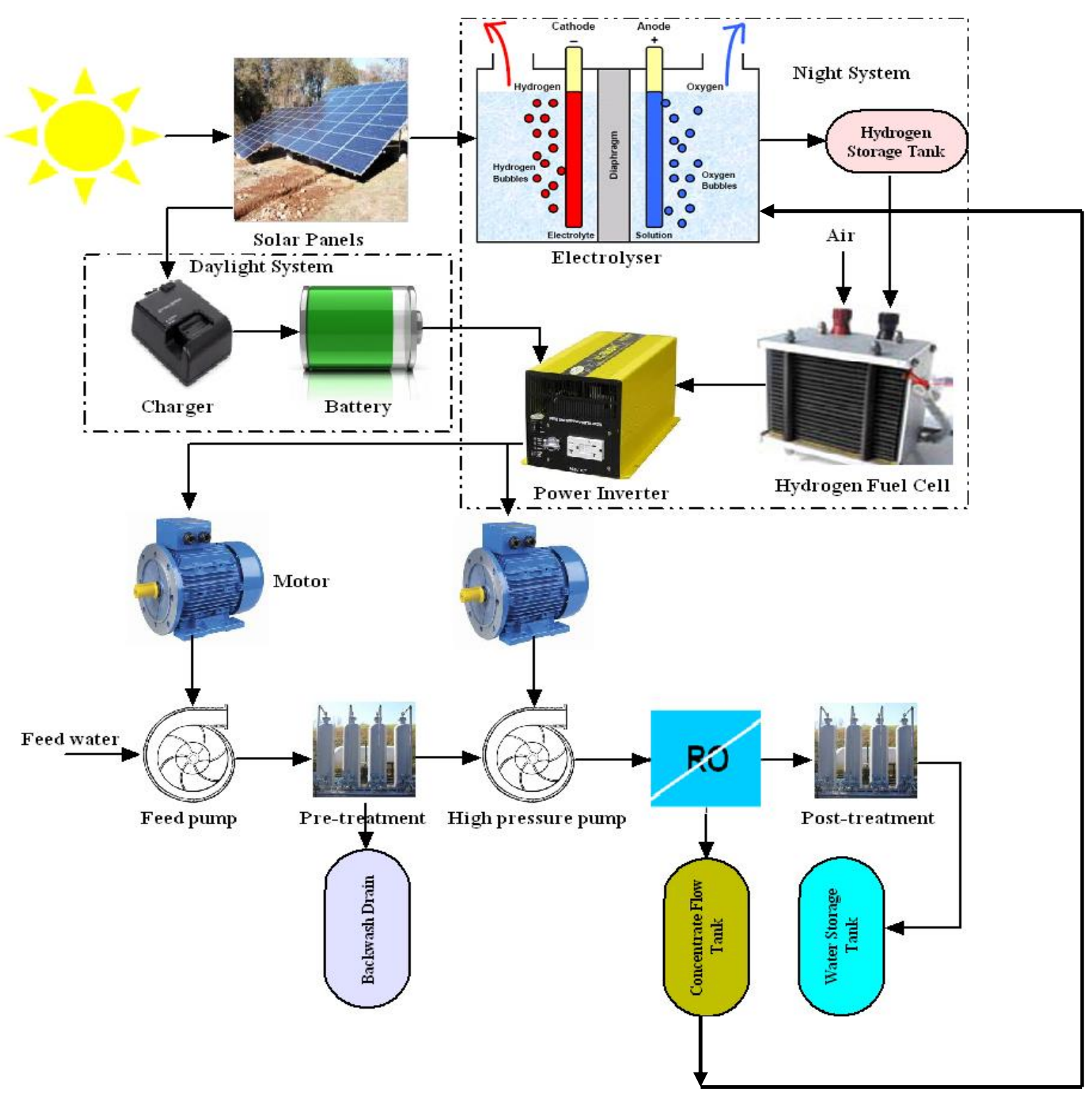

Fig. 3. The proposed HRE-RO system with its component 


\section{Schematic of HRE-RO Desalination System}

The designed HRE-RO system can be seen in Fig. 3. The system can be switched between day and night in order to obtain a continuous production of fresh water. The daylight cycle works directly from sun energy, while the night system is dependent on the storage of solar energy in form of hydrogen energy using a special sea water electrolyser. The hydrogen is then delivered to a hydrogen-fuel cell unit for electricity production. The RO system is designed to run independently of the kind of energy supplied. The descriptions of the proposed system-stages and its components are given following in details.

\section{Stages of the renewable energy system}

\subsection{Solar Panels System}

The first stage of the energy system is the production of DCpower using solar panels. The solar panels or photovoltaic panels are usually used to generate and supply electricity in commercial and residential applications. Because of the limited amount of power produced from each panel; 100-450 watts; most installations contain multiple panels. A photovoltaic system typically includes a solar tracker.

\subsection{Sea water electrolyser}

There are numerous studies in the literature on various aspects of solar hydrogen energy system. A brief review of such system and its performance can be found in $[8,9,10]$. However, the production of hydrogen from sea water using renewable energy system becomes a reality thanks as well as a very common topic to energy research in Egypt as it is now being the key solution of different energy/water problems including global warming and reserves of liquid hydrocarbon fuels. The chief problem is the evolving of chlorine and oxygen at the anode of electrolyser and hydrogen at the cathode during the electrolytic process. Several concepts have been discussed for the direct production of hydrogen from sea water [11]

More recently, a new concept has been applied for seawater electrolysis, where the anodic reaction should not form chlorine but oxygen [12]. This technology can reduce the environmental problem of chlorine discharge during hydrogen production from seawater electrolysis. Consequently, our proposed system considers this new technology in the seawater electrolysis.

\subsection{Hydrogen fuel cell}

Hydrogen fuel cells can be considered today as one of the most promising up-and-coming clean power sources. Fuel cells have been used for decades for power generation at a variety of commercial and industrial sites. The implementation of fuel cells in small system/home power applications has so far been limited due to cost considerations. However, prices are falling and fuel cells should emerge as a viable home power source within the near future. The hydrogen fuel cell has been incorporated previously in different hybrid wind energy systems $[13,14]$. In our proposed model, the hybrid solar energy system is applied for the hydrogen fuel cell.

\section{Stages of the RO system}

In the present section, a brief description of the typical RO system is given. More details about such system and its performance, operating conditions can be found in details in [5].

\subsection{Pretreatment System}

Feed pretreatment is necessary in all desalination methods, and reverse osmosis is no exception. The proper pretreatment of water before it reaches the membrane is the key to successful operation of a reverse osmosis plant. The need for pretreatment depends on the feed water composition, the recovery of the RO system, and the solubility of the particular salt.

\subsection{High-Pressure Pump}

The function of this component is to raise the pressure of the pretreated feed water to the level appropriate for the membrane and for the feed water being used.

The pressure required depends on the concentration and temperature of the feed water. Osmotic pressure increases with increasing concentration, so that the operating pressure must exceed the osmotic pressure corresponding to the concentration of the rejected brine at the membrane outlet. It can be up to three times the osmotic pressure for sea water desalination. Brackish water requires 17-27 bar, where as sea water operates in the range of 50-80 bar. Figure (4) depicts the osmotic pressure of sodium nitrate, sodium chloride, sodium sulfate, and sea water as a function of salt content at $25^{\circ} \mathrm{C}$. In addition, osmotic pressure increases as the temperature increases.

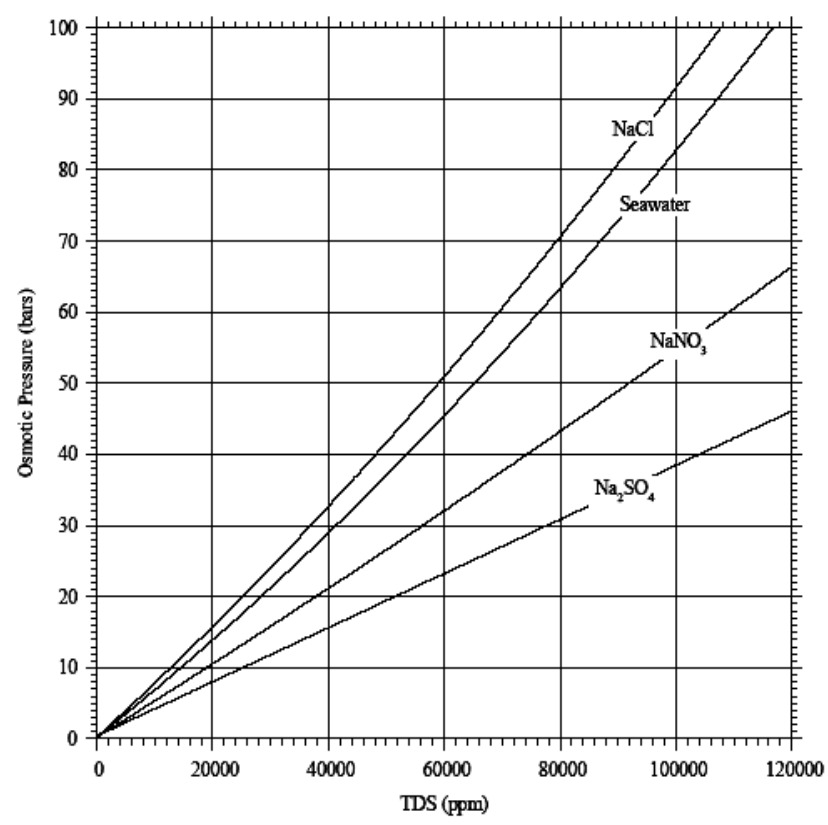

Fig. 4. Osmotic Pressures of Sodium Nitrate, Sodium Chloride, Sodium Sulfate and Sea Water at $25{ }^{\circ} \mathrm{C}$ [3].

\subsection{Membrane Assembly}

Original membranes were made from cellular acetate. Since then, RO processes use a variety of blends or derivatives of cellular acetate, polyamides. Plate-and-frame, tubular, spiralwound and hollow-fine-fiber membranes are the most popular reverse osmosis devices. An ideal membrane has the following characteristics: 
- High salt rejection.

- High permeability to water.

- Resistant to high temperature.

- Resistant to oxidizing agents, especially chlorine.

- Resistant to all kind of fouling (inorganic, organic, colloidal, and microbiological fouling).

- Chemically, physically, and thermally stable in saline water.

- Capable of being formed to yield high membrane area-tovolume ratio (packing density).

- Resistance to creep deformation.

- Long and reliable life.

- Inexpensive.

The membrane performance can be affected by a number of factors according to the feed water characteristics, membrane type and the operating variables. A sketch of such factors affecting the membrane performance can be seen in figure 5 .

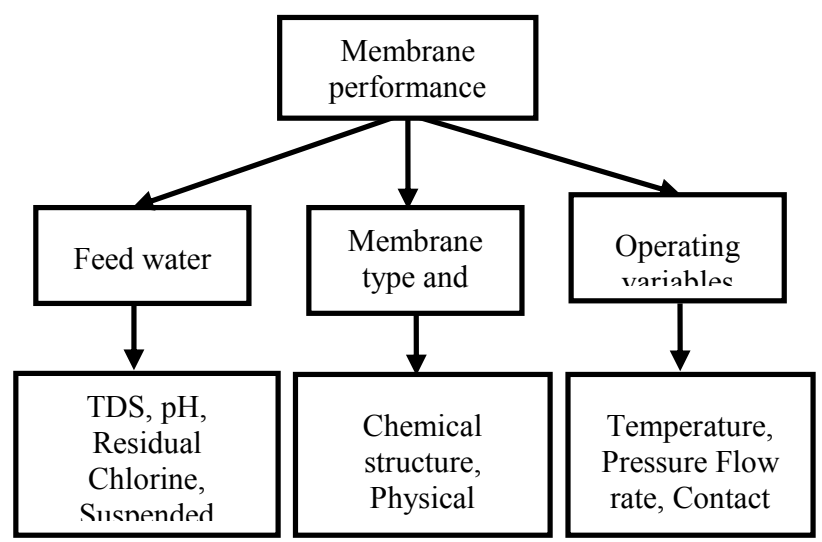

Fig. 5. Factors Influencing the Membrane Performance.

\subsection{Post-Treatment System}

Product water from the RO plant requires treatment prior to storage and transmission to consumers. This is necessary as the product water can cause serious corrosion problems in the pipe transmission system. The product from the membrane usually requires $\mathrm{pH}$ (potential Hydrogen) adjustment. This is done by adding a base or by degasification ( $\mathrm{H} 2 \mathrm{~S}$ and $\mathrm{CO} 2)$. Since most $\mathrm{RO}$ membranes reject calcium in preference to sodium, this necessitates the addition of calcium salts (calcium carbonate or sodium carbonate/bicarbonate) to the product water. Finally, product water requires disinfection to prevent bacterial growth before transferring the product water to the distribution system.

\section{Characteristics of Different RO Desalination System}

In the following table, different RO systems characteristics can be defined. The key parameters are ranged from the system capacity, membrane type, feed temperature and others seen in the table. According to the required system capacity, on can select the suitable system components and the operating variables. Based on such specifications the hybrid energy characteristics can be selected.

\section{Conclusion}

A new idea for a hybrid renewable energy system coupled with reveres osmosis water desalination system is presented. The hybrid energy system is designed in two parts; one for the solar hydrogen production and the second part for the DC electricity production from a hydrogen fuel cell unit. The proposed hybrid energy system is used for providing the RO system with continues (day/night) and clean energy. The proposed standalone unit can become widely utilized not just for drinking water applications but for industrial process applications where high purity is demand. However, extensive studies, either experimentally or numerically, are required to assist the performance of the proposed stand-alone unit. This will be done in the next research.

\section{References}

[1] Kalogirou S. A., "Sea Water Desalination Using Renewable Energy Sources", Energy and Combustion Science 31, pp. 242-281, 2005.

[2] Tiwari G.N., Singh H.N., and Tripathi R., "Present Status of Solar Distillation". Solar Energy 75, pp.367-373, 2003.

[3] Sourirajan S., "Reverse Osmosis". Logos Press Limited, 1970.

[4] Metaiche M. and Kettab A., "Mathematical modeling of desalination parameters: mono-stage reverse osmosis", Desalination 165, pp.153, 2005.

[5] Kotb H." Optimization of Reverse Osmosis Sea Water Desalination Systems" Ph.D. Thesis, Faculty of Engineering, Minoufiya University, Egypt, 2009.

[6] Kotb H., Amer E. H. and Ibrahim K.," Parametric Study of Retentate Re-processing RO Desalination Units" Faculty of Engineering, Minoufiya University, Egypt, Engineering Research Journal, Vol. 32, No. 4, October 2009.

[7] Kotb H., Amer E. H. and Ibrahim K. A." Effect of Operating Conditions on Wall Concentration of RO Systems " Faculty of Engineering, Minoufiya University, Egypt, Engineering Research Journal, Vol. 32, No. 4, October 2009.

[8] Balabel, A. and Zaky, M., "Experimental investigation of solar-hydrogen energy system performance, Int. J. Hydrogen Energy, 36, 4653-4663, 2011.

[9] Mahrous, A. F., Sakr, I. M., Balabel, A. and Ibrahim, K., "Experimental Investigation of the Operating Parameters Affecting Hydrogen Production Process through Alkaline Water Electrolysis", Int. J. of Thermal \& Environmental Engineering, Vol. 2, No. 2, pp. 113-116, 2011.

[10] El-Moneim, A. A., "Novel Anode Materials for Oxygen Evolution during seawater Electrolysis for Green Hydrogen Fuel Production", Int. J. of Thermal \& Environmental Engineering, Vol. 4, No. 1, pp. 33-38, 2012.

[11] EL-Bassuoni, A.-M. A. Sheffieldt, J. W. and Veziroglu, T. N. "Hydrogen and fresh water production from sea water, Int. J. Hydrogen Energy, Vol. 7, No. 12, pp. 919-923, 1982. 
[12] El-Moneim, A. A. and Mohamed, M. B., "New composite Anodes for oxygen Evolution during seawater Electrolysis", Int. J. Electrochem. Sci., 7, 671-685, 2012.

[13] Nelson, D.B., Nehrir, M.H and Wang, C. "Unit sizing and cost analysis of stand-alone hybrid wind/PV/fuel cell power generation systems, Renewable Energy, 31, 16411656, 2006.
[14] El-Shatter, T. F., Eskander, M. N., El-Hagry, M. T. "Energy flow and management of a hybrid wind/PV/fuel cell generation system, Energy Conversion and Management, 47, 1264-1280, 2006.

Table. 1 Characteristics of Different RO Desalination System

\begin{tabular}{|c|c|c|c|c|c|c|}
\hline Item & System (1) & System (2) & System (3) & System (4) & System (5) & System (6) \\
\hline $\begin{array}{l}\text { System capacity } \\
\left(\mathrm{m}^{3} / \text { day }\right)\end{array}$ & 7.6 & 15.1 & 22.7 & 30.2 & 37.8 & 45.3 \\
\hline Membranes type & \multicolumn{6}{|c|}{ Low energy, Thin film(high rejection option) } \\
\hline Membranes number & 1 & 2 & 3 & 4 & 5 & 6 \\
\hline Pump type & $\begin{array}{c}\text { Brass positive } \\
\text { displacement(SS } \\
\text { option) }\end{array}$ & \multicolumn{5}{|c|}{ SS Multi -stage centrifugal } \\
\hline Motor rating(HP) & $1-1.5$ & & & & $2-3$ & $3-5$ \\
\hline Filters & \multicolumn{6}{|c|}{10 micron, $20 "$ pre-filter and housing } \\
\hline Vessels & & & & & & \\
\hline $\begin{array}{c}\text { Max. feed } \\
\text { concentration } \\
(\mathrm{mg} / \mathrm{l})\end{array}$ & \multicolumn{6}{|c|}{5000} \\
\hline $\begin{array}{l}\text { Max. operating } \\
\text { pressure(bar) }\end{array}$ & \multicolumn{6}{|c|}{13.8} \\
\hline $\begin{array}{c}\text { Max. feed } \\
\text { temperature }\left({ }^{\circ} \mathrm{C}\right)\end{array}$ & \multicolumn{6}{|c|}{45} \\
\hline Feed PH & \multicolumn{6}{|c|}{$3-10$} \\
\hline Recovery (\%) & 31 & 48 & 58 & 48 & 54 & 58 \\
\hline $\begin{array}{c}\text { Typical TDS rejection } \\
(\%)\end{array}$ & \multicolumn{6}{|c|}{98} \\
\hline
\end{tabular}

